\title{
Nutrition disparities and the global burden of malnutrition
}

\author{
Strategies to tackle stunting, obesity, and micronutrient deficiencies must take into account the \\ inequities in which these diseases are rooted, argue Rafael Perez-Escamilla and colleagues
}

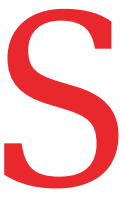

ocial determinants of health are understood to be key to grasping why inequalities in health outcomes exist within, and between, populations. They are also implicated in the differences in dietary intake, dietary patterns, and dietary quality seen in some groups, leading to an unequal burden of disease and morbidity. Nutrition disparities are reflected in the higher prevalence of undernutrition; overweight and obesity (overnutrition); or both, in inequitable social conditions, such as poverty. They happen more often in low and middle income countries (LMICs) compared with high income countries (HICs), and also in subpopulations within these countries. The double burden of malnutrition (DBM) refers to the coexistence of under- and overnutrition that can happen at the individual, household, or population level.

Tackling the coexistence of stunting and overweight (including obesity) has been identified as a formidable challenge for LMICs, requiring integrated, multisectoral actions. ${ }^{12}$ These two DBM components have common elements rooted in the social determinants of health (SDoH). For example, household food insecurity, a condition related to poverty that limits access to a nutritious and safe diet, has been consistently associated with both undernutrition in children and overweight in women. ${ }^{3-5}$ The first 1000 days of life offer a window of opportunity to prevent both stunting and obesity, and are a worthwhile focus for strategies to tackle nutrition disparities.

\section{KEY MESSAGES}

- As a feature of the double burden of malnutrition (DBM), child undernutrition and adult obesity coexist in low and middle income countries (LMICs)

- The DBM in LMICs and obesity in high income countries (HICs) are concentrated among the poor

- Nutrition specific interventions alone have not been able to make a significant dent on the DBM in LMICs

- Multisectoral policies that tackle the social determinants of health are needed to prevent and reduce inequities in undernutrition and obesity globally
The main objectives of this article are to: describe nutrition disparities in stunting in LMICs and obesity in both LMICs and HICs; discuss disparities in micronutrient malnutrition using anaemia as an example; describe the critical role of breastfeeding for maternal-child health and identify challenges to its practice; and consider whether an integrated, equity focused, multisectoral approach, focused on the $\mathrm{SDoH}$, could tackle both stunting and obesity.

\section{The maternal-child life course}

Nutritional disparities and the DBM must be considered from a life course perspective. Research focusing on women of childbearing age living in socioeconomically deprived circumstances has documented the intergenerational transmission of both stunting and obesity. ${ }^{6-8}$ Albeit less studied, paternal excessive body weight has also been associated with increased obesity risk in children. ${ }^{9}$

Over 2 billion people are overweight and almost two thirds live in LMICs. ${ }^{2} 10$ Obesity among women of childbearing age and children is increasing globally. ${ }^{11}$ Women who enter pregnancy overweight are more likely to gain excessive weight during pregnancy, develop gestational diabetes, deliver large for gestational age or premature newborns, and are less likely to breastfeed. ${ }^{11}$ Children born to overweight women have increased risks of developing obesity that persist as they mature. Women then pass to their children an increased risk of obesity that persists into later life, perpetuating the cycle. ${ }^{61213}$

Maternal stunting, underweight, and gaining less weight than recommended during pregnancy are associated with intrauterine growth restriction, which has also been associated with increased risk of stunting. ${ }^{2}$ As with obesity, stunting is transmitted from one generation to the next, possibly through epigenetic mechanisms, ${ }^{14}$ and stunting is a risk factor for the development of obesity. ${ }^{15} 16$ This early onset risk is difficult to reverse after infancy, underscoring the high priority for very early intervention to achieve normal weight among all women and men.

Intergenerational transmission of risk for malnutrition is heightened in the presence of social, economic, and gender inequities. ${ }^{617}$ The challenges associated with facilitating optimal pre-conception nutrition are rooted in many societal processes and sectors. These need to be tackled by equity focused policies and systems through changes in community capacity building, advocacy, and political will $^{718-20}$ (fig 1).

\section{Patterns of nutrition disparities}

To have a better understanding of socioeconomic inequities in nutrition outcomes across countries with different levels of economic development, this section first presents data on the distribution of stunting, obesity, and anaemia among LMICs, followed by the distribution of obesity in HICs as a function of family socioeconomic status.

Iron deficiency anaemia was chosen because it is the most common micronutrient deficiency related condition all over the world, ${ }^{21}$ there are clear inequities in its distribution, and it has proven to be difficult to tackle through simple supplementation or fortification. ${ }^{2223}$

\section{Stunting, obesity, and anaemia in low and} middle income countries

An analysis of 80 countries by world regions, as classified by UNICEF, shows that stunting and overweight are not randomly distributed within any given population. In all regions, stunting prevalence among children under 5 decreases as wealth increases (fig 2). The highest prevalence of stunting and widest wealth driven gaps are in south Asia, and the narrowest in eastern Europe and central Asia.

By contrast, child overweight (fig 3) is positively associated with wealth in all regions, with west and central Africa showing the smallest gaps. However, although absolute obesity prevalences are still higher among the wealthier in LMICs, obesity rates are growing much faster among the socioeconomically vulnerable, including indigenous groups defined as the original inhabitants of a region. ${ }^{2425}$

Inequities are also present with respect to iron deficiency anaemia, which is highly prevalent among young children in LMICs. Demographic and Health Survey (DHS) data, collected between 2005 and 2016 from 52 low, lower-middle, and uppermiddle countries, showed an overall 


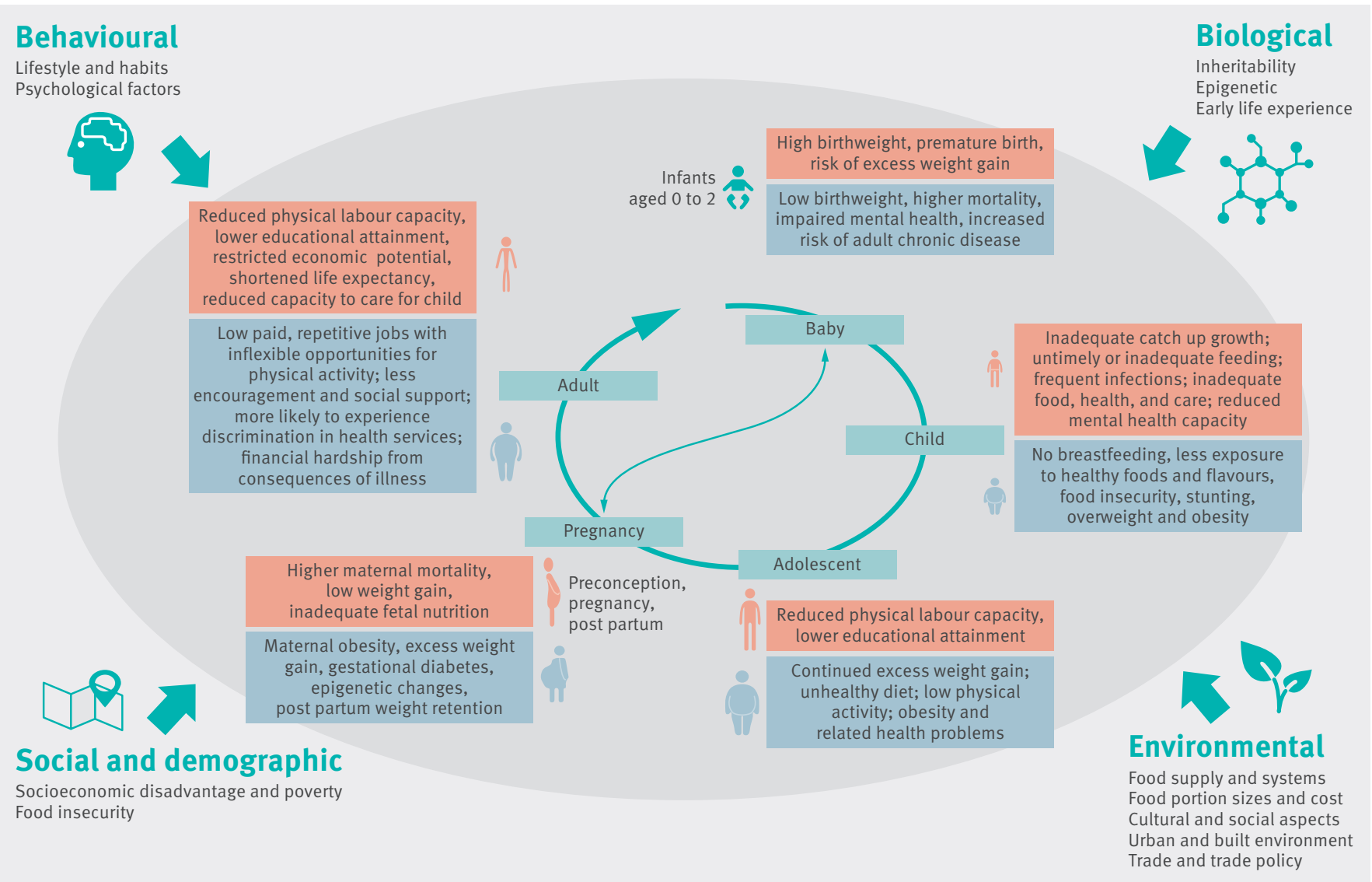

Fig 1 | The double burden of malnutrition through the life cycle and across generations and shared drivers ${ }^{1719}$

anaemia prevalence of $54.2 \%$ among children less than 5 years old. Disparities were found as a function of both World Bank country income classification ${ }^{26}$ and wealth index as defined by DHS. ${ }^{27}$ The unweighted mean prevalence of anaemia was highest in the 22 lower income countries $(61.7 \%)$ and lowest in the six upper-middle income countries (39.4\%), and in between in 24 lower-middle income countries (51.7\%). Consistent with these

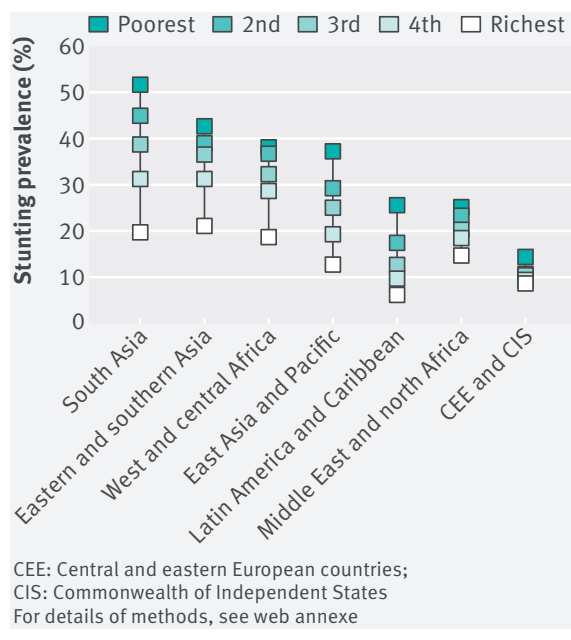

Fig 2 Stunting prevalence in children under 5 years old, according to wealth quintiles by world regions ordered by prevalence in the poorest quintile findings, in all three country income groupings, children in households in the poorest quintile had the highest anaemia prevalence and those in households in the wealthiest quintile had the lowest (fig 4).

Obesity inequities in high income countries Both maternal and child obesity are more prevalent among the poor in HICs. ${ }^{28} 29$ However, an initial pattern of more obesity among the wealthy is seen where

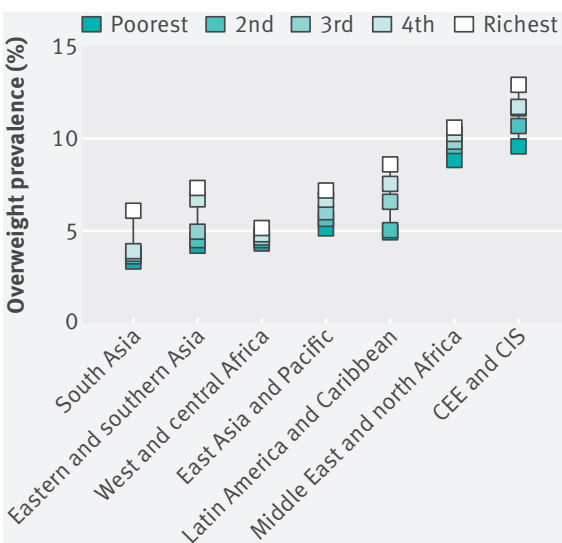

CEE: Central and eastern European countries: CIS: Commonwealth of Independent States For details of methods, see web annexe

Fig 3 Overweight prevalence in children under 5 years according to wealth quintiles, by world regions ordered by prevalence in the poorest quintile undernutrition among the poor is still the predominant problem. ${ }^{30}$ As previously indicated, overweight prevalence is increasing rapidly among the poor, including in rural areas and indigenous communities. ${ }^{31}$ Prevalence increases with social disadvantage, as illustrated for the US and England in figs 5 and $6 .^{3233}$ Additionally, inequities affecting ethnic minority populations are pronounced (figs 7 and 8). ${ }^{3233}$ Children in ethnic minority populations living in HICs, including the US, often experience social inequities disproportionately. ${ }^{34}$

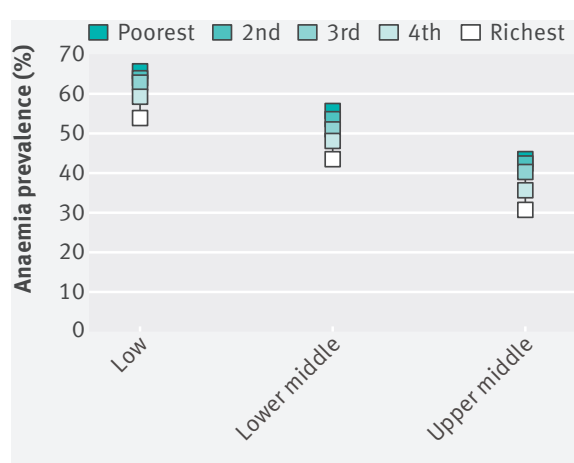

From the Demographic and Health Survey Stat compiler www.statcompiler.com

Fig 4 | Percentage of children less than 5 years old with anaemia $(\mathrm{Hb}<11 \mathrm{~g} / \mathrm{dL}$ ) by World Bank country income classifications and Demographic and Health Surveys wealth index 


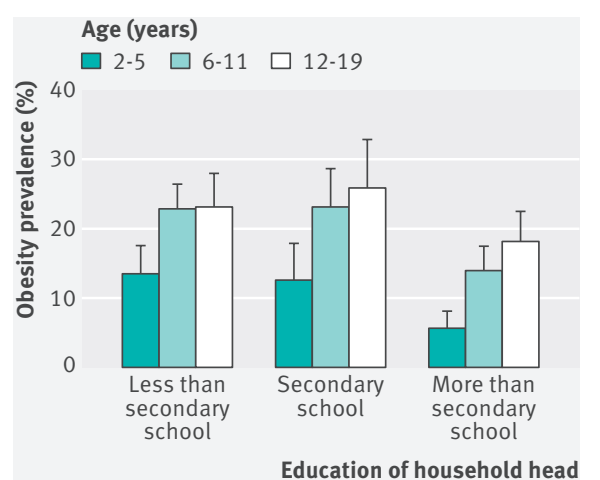

Fig 5 |Association of childhood obesity with educational attainment in the US

\section{Strategies for tackling undernutrition and overweight}

Given the well established excessive stunting risk among the poor, and the growing concentration of overweight in socioeconomically vulnerable groups, it is important to explore potential solutions to the DBM in LMICs and the obesity epidemic in HICs at different levels of the socioecological model, taking into account other nutrition related problems, including anaemia (box 1).

There is increasing recognition that early life strategies to tackle undernutrition should take into account other forms of malnutrition, including obesity. ${ }^{1835}$ Otherwise, solving one problem can magnify another. Global food security initiatives, for example, often promote the production and availability of specific staple crops such as grains or starchy vegetables. Such programmes have succeeded in increasing the availability of plant protein and food energy, ${ }^{36}$ but have been criticised for distorting markets and potentially promoting obesity and noncommunicable disease (NCD) risk by making healthier foods less affordable for consumers, leading to less varied, more energy dense diets for consumers. ${ }^{37}$ International initiatives for food security are now considering balancing

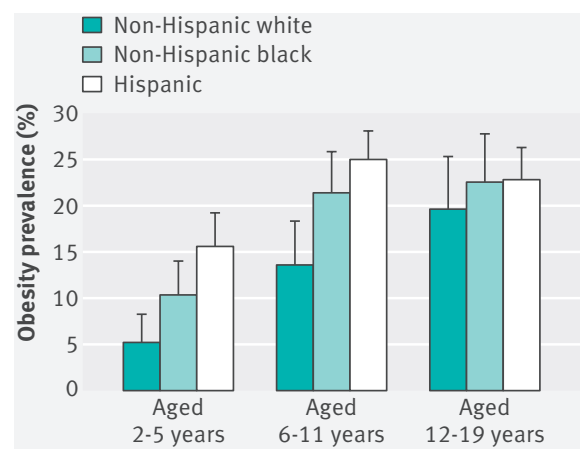

Fig 7 | Obesity prevalence among US children from diverse racial groups

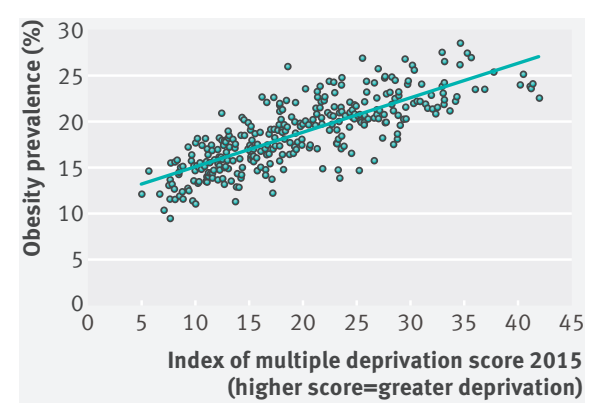

Fig 6 | Association of overweight children with neighbourhood deprivation, 10-11 year old children in England

programmes focused on protein energy malnutrition and micronutrient deficiency with obesity prevention initiatives. ${ }^{53538}$

\section{Undernutrition}

Stunting

Prevention of child stunting through nutrition specific interventions, such as lipid based nutrient spreads (LNSs), has been suggested, but effectiveness trials have had mixed results. ${ }^{39-41}$ A recent review found that small quantity (SQ)-LNS are generally well accepted but remain unproven for efficacy in improving linear growth or preventing growth faltering. ${ }^{39}$ These findings are consistent with an expert review of eight pregnancy and early childhood randomised controlled trials (RCTs) conducted in Asia, Africa, the Caribbean, and Latin America. ${ }^{41}$ Thus, drawing on insights from the social ecological model, which postulates that health behaviours are shaped by the interactions of people with their larger social, cultural, economic, and environmental contexts, ${ }^{42}$ tackling stunting simply as a food problem to be solved with nutrition specific interventions in the absence of tackling SDoH is not enough. ${ }^{43}$

As described above, stunting in children is more concentrated in LMICs where living standards are suboptimal-these environments asssre characterised by poor environmental sanitation, poverty, food insecurity and hunger, and lack of access to quality healthcare and education. Countries like Brazil, Chile, and Peru have been successful at tackling chronic malnutrition through more equitable social and economic policies. ${ }^{44-46}$ The case study of Brazil illustrates the value of nutrition sensitive interventions in concert with those focused on SDoH (box 2). Tackling stunting does require effective and equitable policies and civil society participation in governance structures that facilitate inclusive, equitable, and sustainable economic growth: multisectoral strategies that tackle cultural diversity, eating styles, and both local and global food systems, ${ }^{47}$ as well as access to clean water and sanitation, healthcare, and education. $^{48}$

Anaemia

Systematic reviews of several RCTs of micronutrient powders (MNPs) in Africa, Asia, and the Caribbean have found a reduction in the risk of anaemia and iron deficiency of around $30 \%$ and 50\%, respectively. ${ }^{4950}$ A recent Cochrane review that included 13 RCTs from Africa, Asia, and Latin America found that provision of MNPs (containing between 2 and 18 vitamins and minerals) to young children led to lower risk of anaemia and iron deficiency. ${ }^{51}$ However, although MNP interventions were overall well accepted, adherence was context specific and in several studies comparable to the same benefit as using standard iron supplementation interventions. ${ }^{50}$ In addition, the effect of MNPs on diarrhoea risk needs to be further examined. ${ }^{51}$ LNS interventions havsse also reduced anaemia prevalence ${ }^{4041}$ although it is unclear if either MNPs or LNSs provide benefits above and beyond standard approaches. ${ }^{50}$ As with stunting, ${ }^{48}$ sustainable reductions in anaemia prevalence require well coordinated, effective, multisectoral policies that include health, nutrition, agriculture, water and sanitation, education, and social protection sectors. $^{52}$ 


\section{Box 1: Nutrition disparities: where do we go from here?}

\section{Context}

- Poverty and other social inequities are associated with poor nutrition in both LMICs and HICs, also among certain population subgroups within countries

- The double burden of malnutrition (DBM), defined as the coexistence of undernutrition (for example, stunting) and overnutrition (overweight or obesity) at the population, family, or individual level, is highly prevalent in LMICs

- HICs are experiencing a major obesity epidemic. Socioeconomic inequities have been associated with both under- and overnutrition within HICs

What is known

- In all regions where LMICs are located, stunting prevalence among children under 5 is inversely associated with family wealth

- The prevalence of adult obesity continues to concentrate more among the poor in LMICs and in the US

- The obesity epidemic continues to be unabated in HICs. Multisectoral life course strategies are needed to tackle it

- DBM occurs in the context of widespread micronutrient deficiencies

- LMICs do not have well coordinated strategies to effectively tackle the DBM

Areas of consensus

- Tackling inequities in the distribution of the DBM in LMICs and the obesity epidemic in HICs requires also tackling the social determinants of health, including access to food security, healthcare, education, and jobs that pay reasonable wages

- Nutrition specific interventions during the first 1000 days of life including preconceptional nutrition, nutrition during pregnancy, and optimal breastfeeding and complementary feeding are key for tackling the prevention of infectious diseases and non-communicable diseases globally.

- The DBM requires avoiding strategies that solve one nutrition problem while magnifying another one such as the use of sugar as a vehicle for micronutrient fortification.

Areas of controversy

- We don't know if micronutrient specific interventions such as lipid nutrient supplements reduce the risk of stunting in low income countries

- It's unclear how to improve access to social determinants of health in different contexts given that this requires equitable and sustainable economic growth which is lacking among the populations that are most vulnerable to experiencing nutrition inequities

Future directions in this field

- Implementation of science research based on complex systems frameworks is needed for understanding how to scale up cost effective, multisectoral interventions that can simultaneously tackle stunting, overweight, and micronutrient deficiencies

\section{Box 2: How did Brazil reduce levels of stunting and change breastfeeding practices?}

Brazil has shown impressive improvements in stunting levels and breastfeeding practices since the mid-1970s. ${ }^{46109}$ Stunting prevalence among children younger than 5 years has dropped from $37 \%$ in 1975 to $19 \%$ in 1989 and to $7 \%$ in 2007. Exclusive breastfeeding ( $<6$ months) underwent a remarkable improvement from $4.7 \%$ in 1986 to $37 \%$ in 2006 and relative stabilisation between 2006 and $2013^{109}$; during the same period, the median duration of breastfeeding increased from around 2.5 months to 14 months. ${ }^{46}$

This progress is derived from a strong political commitment in reducing malnutrition and corresponding inequities following a socioecological approach. Up to the mid-2010s, Brazil had tackled three key components of social determinants of health and nutrition through well thought out multisectoral policies ${ }^{46}$ reflected in: more equitable wealth distribution; improved social protection and public health programmes (for example, conditional cash transfer programme Bolsa Família and improvements in water and sanitation); restructuring and strengthening of the health sector by expanding coverage and quality of public health programmes (promotion of breastfeeding, oral rehydration, and immunisations), universal healthcare coverage, and implementing multiple national and state-wide effective maternal and child health and nutrition programmes and policies, including paid maternity leave.

This case study illustrates that improving breastfeeding and reducing stunting require both nutrition sensitive and nutrition specific approaches delivered though a socioecological, multisectoral, well coordinated framework. ${ }^{79 s s}$

\section{Overweight}

The social ecological model has also widened our understanding of the causes of obesity beyond biomedical or psychological paradigms. Population level obesity is recognised as the result of the complex, multilevel interplay of biology, behaviour, and environments. ${ }^{53}$ For management of obesity and prevention in high risk groups, there is a role for individual level intervention in clinical and community settings. However, relative increases in inequities associated with social disadvantage indicate that current individually focused obesity prevention efforts in the absence of structural changes to facilitate behaviour changes may be doing harm by widening wealth driven inequities. ${ }^{12}$ To be broadly effective, population level obesity prevention must account for the wider social and environmental contexts in which people make food choices. ${ }^{54}$ Specifically, obesity prevention requires collectively tackling behavioural, biological, environmental, social, and demographic drivers from the individual level to the population level, paying strong attention to equity (fig 1).

Consumer oriented policies are an important focus of strategies to tackle obesity. In HICs, reconciling the roles and responsibilities of individuals, communities, governments, and markets has been a major challenge. ${ }^{55}$ Although there is consensus that tackling unhealthy eating behaviours is fundamental for curbing the obesity and NCDs epidemics, ${ }^{1056} 57$ there is limited agreement on how this should be achieved. The dominant paradigm of placing responsibility with the consumer, exemplified by individually focused education, is now shifting to population level consumer information based interventions, such as menu labels in restaurants, ${ }^{58}$ labels on manufactured foods, ${ }^{59}$ and nutrition oriented shelf labels in supermarkets. ${ }^{60}$ The impact of informational approaches has been limited, in part because the majority of food related decisions are not the result of rational reflection and deliberation, but rather automatic and habitual behaviours, cued by the food retailing environment and reinforced by cultural norms. ${ }^{61}$ Moreover, information based approaches can potentially widen inequalities, because they generally work best in higher socioeconomic status populations, which have more psychosocial and material resources to act upon health related information. ${ }^{62}$ This reinforces the importance of tackling these epidemics through multisectoral policies that tackle the SDoH. ${ }^{38}$

\section{Critical role of breastfeeding}

Whereas above we discussed the highly specific micronutrient fortification 
interventions as a way to tackle anaemia, it is important to also take into account that there are key nutrition specific interventions, such as breastfeeding, that involve complex maternal-infant behaviours and their interactions within the context of their surrounding social, economic, and cultural environments. Breastfeeding is an example of an early life nutrition behaviour that has implications for both undernutrition and infectious diseases, as well as obesity and chronic diseases in the child, and also offers major health benefits to the mother.

There are also exclusive breastfeeding inequities that need to be tackled through the socioecological model lens. ${ }^{63}$ Sufficient duration of breastfeeding is critical for maternal and child health ${ }^{64}$ and also facilitates obesity prevention, especially for children at high biological risk of excess weight gain. ${ }^{65-67}$ Breastfeeding may also help to break the cycle of intergenerational transmission by facilitating maternal postpartum weight loss, ${ }^{68-70}$ decreasing the mother's risk of being more overweight in a subsequent pregnancy. This applies especially in HICs but is becoming relevant to those LMICs where the majority of women of reproductive age are overweight or obese. ${ }^{6971}$ Overall, breastfeeding prevalence and duration are lower and obesity rates higher in HICs than in LMICs $^{64} 6872$; obesity is more common among women in low income and ethnic minority populations in $\mathrm{HICs}^{32}{ }^{73}$; and breastfeeding is less common among women with obesity. ${ }^{6874}$

Breastfeeding traditions in some indigenous and established or new immigrant racial or ethnic minorities in HICs may be associated with higher breastfeeding prevalence compared with the host population but may not be sustained with continued exposure to contexts that favour formula feeding. ${ }^{75}$ Breastfeeding promotion involves "baby friendly" initiatives in hospitals and various education and counselling approaches to motivate and support breastfeeding in community and family settings. ${ }^{76}$ Studies in diverse countries indicate that such interventions typically improve one or more key breastfeeding outcomesinitiation, duration, or exclusivity ${ }^{77}-$ in some cases with relatively larger effects among women in less educated or ethnic minority populations that have especially low breastfeeding rates. ${ }^{76}$ Breastfeeding in LMICs tends to last longer among poorer and rural women than in the rest of the population, and breastfeeding is one of the few healthy behaviours that are more common among the poor. However, in several middle income countries breastfeeding rates are increasing among high income women while declining among low income and indigenous women. ${ }^{78}$

Improving breastfeeding duration and exclusivity require policy based interventions that empower women and their families. ${ }^{7679}$ Relevant policy targets include: infant formula marketing regulation through enforcement of the international code of marketing of breastmilk substitutes and subsequent relevant World Health Assembly resolutions ${ }^{80}$; pre-service breastfeeding education and training in medical, nursing, and allied health schools; breast pump access; family leave policies; flexibility of work hours or locations, and protections for women in informal work sectors; and accommodations for breastfeeding mothers in workplaces and childcare settings. ${ }^{749}$ Empirical evidence for the effectiveness of such policy approaches relies primarily on observational studies but is consistent with the underlying known structural factors affecting breastfeeding. ${ }^{79} 81$ The case of Brazil illustrates how nutrition sensitive and nutrition specific interventions through a social ecological, multisectoral, well coordinated framework can have an impact on improving breastfeeding outcomes $^{79}$ (box 2).

\section{Tackling the social determinants of health}

Given the central role that social determinants of health play in nutrition and health outcomes across the life course, strategies that tackle social determinants will be key to tackling the DBM in LMICs and the obesity epidemic in HICs. The social ecological model has been used to understand the aetiology of child undernutrition ${ }^{82}$ and overweight across the life course, ${ }^{4283}$ without recognising that both may have common structural determinants. The common pathways suggest the potential for integrated SDoH strategies. ${ }^{13584}$ The recent trend of tackling economic and environmental determinants of unhealthy diets will likely result in greater equity in obesity prevention in HICs and may also be effective for tackling obesity in LMICs. ${ }^{66}$ In these countries, rising consumption of processed food products high in sugar, salt, and fats has been attributed largely to structural factors stemming from economic development, particularly rising incomes, urbanisation, and globalising economies enabling foreign investment, and imports of cheap, processed foods. ${ }^{10308586}$ Food consumption is inherently an economic activity, with implications for the political economy of the food system, and the interests of powerful stakeholders within it. In the long term, agriculture sector policies that prioritise commodity crops that provide a cheap and steady source of starch, fat, and sugar in the food supply will need to change consist- ent with public health goals. ${ }^{87}$ Fiscal incentives for the production of a variety of fruits, vegetables, and sustainable protein sources should be considered..$^{5788}$

Fiscal, demand side interventions are also important for tackling undernutrition in LMICs, but unintended consequences may arise. Conditional cash transfer programmes (CCTs), which provide cash to poor households that agree to participate in education and health promotion activities, have reduced child stunting in some settings and population subgroups..$^{89-91}$ However, CCTs have also been associated with increased risk of obesity and greater intake of sugar and sugar sweetened drinks among adults. ${ }^{899293}$ CCTs are designed to supplement the incomes of low income families and can be used for anything the family needs or wants, not only food, as long as they meet the programme conditions (participation in education and health services). Studies have shown, however, that CCT funds do help reduce food insecurity in target families. ${ }^{91}$

Another fiscal demand side intervention indicates that subsidies for healthy foods in the form of vouchers or discounts ranging from $10 \%$ to $50 \%$ can have beneficial effects on food purchasing in LMICs. ${ }^{6694-97}$ Targeted food taxes may also be effective. The tax on sugar sweetened beverages and energy dense snack foods in Mexico ${ }^{98}$ has reduced the purchase of these products, with effects strongest in lowest income households. ${ }^{66}$ Likewise, Hungary's tax, which is partly determined by sugar content of food and drink, has resulted in a substantial decline in consumption of the taxed products. ${ }^{99}$ Preliminary evaluations of more recently implemented taxes on sugar sweetened drinks in Chile, ${ }^{100}$ Barbados, ${ }^{101}$ South Africa, and some US municipalities are showing promising results. $^{102}$

\section{Implications for dietary guidelines}

Tackling the DBM requires taking into account food systems in the context of socioeconomic inequities. Therefore, it is key for influential policy instruments, such as government issued dietary guidelines, to take these inequities into account when selecting evidence based policies and programmes. The DBM demands a new strategy for dietary guidelines that seek to simultaneously curb the stunting, obesity, and micronutrient deficiency epidemics while taking into account the profound inequities upon which they are rooted. Food based dietary guidelines are needed not only for consumers but also for providers across sectors and for the development of evidence based policies and programmes. ${ }^{103-105}$ Dietary guidelines and ancillary products are being issued 
globally ${ }^{106} 107$ but few tackle the importance of the first 1000 days for stunting and obesity prevention. Likewise, very few are grounded on the principles of responsive parenting and feeding which has been shown to be crucial for childhood obesity prevention. ${ }^{107}$ Future guidelines will need to take this knowledge into account as well as the increasing evidence on effective policies to implement the WHO code on marketing of breastmilk substitutes ${ }^{80}$ and subsequent relevant World Health Assembly resolutions, and to limit consumption of unhealthy foods and drinks, provide consumers with more information, and encourage product reformulation to reduce or eliminate added sugars and trans fats. ${ }^{64}$

\section{Conclusions}

Can an integrated multisector strategy can be designed to prevent both stunting and obesity in LMICs? International development agencies have identified the development of multicomponent strategies to tackle the coexistence of contrasting forms of malnutrition across the life course as a priority. This should be possible because, as the evidence presented here highlights, common drivers of the food and nutritional components of the DBM, and the obesity epidemic in HICs, are: intergenerational transmission; environmental and socioeconomic influences (for example, the ability to access nutritious foods and adopt healthier nutrition habits and behaviours); and a lack of shared multisectoral delivery platforms (fig 1). Common platforms for delivering actions can offer an opportunity for alignment and coordination of cost effective integrated actions and can be a catalyst for tackling policy challenges beyond health-including reducing health and social inequities within populations and raising educational attainment. ${ }^{35}$ It is important to acknowledge that, even though multisectoral coordination is needed for delivery of effective programmes to prevent stunting, obesity, and micronutrient deficiencies through common interventions, recovery from stunting and obesity does require different sets of interventions once these conditions are established.

Our conclusions are congruent with the “double duty actions" recently proposed by WHO. ${ }^{35}$ These actions call for policies and programmes that can simultaneously reduce the risk or burden of both undernutrition and overweight, obesity, or diet related to NCDs through common interventions following three levels of recommended actions ${ }^{35}{ }^{108}$ : ensuring that current interventions, policies, and programmes designed to tackle one form of malnutrition do not inadvertently increase the risk of another (for example, sugar fortification with micronutrients, or agricultural policies that foster the consumption of energy dense foods and sugar sweetened beverages); leveraging existing actions designed to tackle one type of malnutrition to simultaneously reduce other types, especially maternalchild nutrition programmes during the first 1000 days; and identifying the shared upstream nutrition sensitive drivers between different forms of malnutrition (such as food systems). Tackling the double burden of malnutrition through double duty equitable actions will be of critical importance in achieving both the ambitions of the UN's Decade of Action on Nutrition and the Sustainable Development Goals. ${ }^{108}$ Implementation science research based on complex systems frameworks is needed for understanding how to scale up cost effective, multisectoral interventions that can simultaneously tackle stunting, overweight, and micronutrient deficiencies.

We thank the World Health Organization, Department of Nutrition for Health and Development, Evidence and Programme Guidance which generously provided the DHS analyses on anaemia used in the paper.

Contributors and sources: SK and PM contributed to the review of obesity inequalities and population level prevention of obesity. CV contributed with the epidemiological analysis of stunting and obesity disparities. CL and OB contributed with anaemia review. RPE, GSB, and SK contributed with policy and breastfeeding reviews. RPE conceptualised and drafted the initial manuscript outline, all authors participated in the writing and critical review of manuscript drafts. RPE is the guarantor of this article.

Competing interests: We have read and understood BMJ's policy on declaration of interests and all authors declare they have no conflict of interests.

Provenance and peer review: Commissioned; externally peer reviewed.

This article is one of a series commissioned by The $B M J$. Open access fees for the series were funded by Swiss Re, which had no input into the commissioning or peer review of the articles.

Rafael Perez-Escamilla, professor of public health ${ }^{1}$ Odilia Bermudez, associate professor of public health and community medicine 2

Gabriela Santos Buccini, postdoctoral associate ${ }^{1}$ Shiriki Kumanyika, research professor ${ }^{3}$

Chessa K Lutter, senior nutrition researcher ${ }^{4}$ Pablo Monsivais, associate professor ${ }^{5}$ Cesar Victora, emeritus professor of epidemiology ${ }^{6}$ ${ }^{1}$ Yale School of Public Health, New Haven, Connecticut, USA

${ }^{2}$ Tufts University, Boston, USA

${ }^{3}$ Drexel University, Philadelphia, USA ${ }^{4}$ RTI International, Washington DC, USA ${ }^{5}$ Washington State University, Spokane, USA ${ }^{6}$ Federal University of Pelotas, Pelotas, Brazil Correspondence to: R Perez-Escamilla rafael.perez-escamilla@yale.edu

World Health Organization (WHO). The double burden of malnutrition. Policy brief. World Health Organization, 2017

Black RE, Victora CG, Walker SP, et al, Maternal and Child Nutrition Study Group. Maternal and child undernutrition and overweight in low-income and middle-income countries. Lancet 2013;382:427-51. doi:10.1016/S0140-6736(13)60937-X

Gubert MB, Spaniol AM, Segall-Corrêa AM, PérezEscamilla R. Understanding the double burden of malnutrition in food insecure households in Brazil. Matern Child Nutr 2017;13. doi:10.1111/ mcn.12347

4 Shamah-Levy T, Mundo-Rosas V, Morales-Ruan C, Cuevas-Nasu L, Méndez-Gómez-Humarán I,

Pérez-Escamilla R. Food insecurity and maternalchild nutritional status in Mexico: cross-sectional analysis of the National Health and Nutrition Survey 2012. BMJ Open 2017;7:e014371. doi:10.1136/ bmjopen-2016-014371

Farrell P, Thow AM, Abimbola S, Faruqui N, Negin J. How food insecurity could lead to obesity in LMICs: When not enough is too much: a realist review of how food insecurity could lead to obesity in low- and middle-income countries. Health Promot Int 2017. doi:10.1093/heapro/dax026

6 Pérez-Escamilla R, Bermúdez O. Early life nutrition disparities: where the problem begins? Adv Nutr 2012:3:71-2. doi:10.3945/an.111.001453 Pérez-Escamilla R, Kac G. Childhood obesity prevention: a life-course framework. Int J Obes Suppl 2013;3(Suppl 1):S3-5. doi:10.1038/ ijosup.2013.2

8 Every Woman Every Child. Nutrition and women's, children's and adolescents' health. 2015. www.everywomaneverychild.org/wp-content/ uploads/2015/02/09_Nutrition_and_womens_ childrens_and_adolescents_health_230315. FB 2015-03-24.pdf.

9 Veena SR, Krishnaveni GV, Karat SC, Osmond C, Fall CH. Testing the fetal overnutrition hypothesis; the relationship of maternal and paternal adiposity to adiposity, insulin resistance and cardiovascular risk factors in Indian children. Public Health Nutr 2013;16:1656-66. doi:10.1017/ S1368980012003795

10 Ford ND, Patel SA, Narayan KM. Obesity in low and middleincome countries: burden, drivers, and emerging challenges. Annu Rev Public Health 2017;38:145-64. doi:10.1146/annurevpublhealth-031816-044604

11 Poston L, Caleyachetty R, Cnattingius S, et al. Preconceptional and maternal obesity: epidemiology and health consequences. Lancet Diabetes Endocrinol 2016;4:1025-36. doi:10.1016/S22138587(16)30217-0

12 World Health Organization. Report of the Commission on Ending Childhood Obesity. World Health Organization, 2016.

13 Dolton P, Xiao M. The intergenerational transmission of body mass index across countries. Econ Hum Biol 2017;24(Supplement C):140-52 doi:10.1016/i.ehb.2016.11.005

14 Martorell R, Zongrone A. Intergenerational influences on child growth and undernutrition. Paediatr Perinat Epidemiol 2012;26(Suppl 1):302-14. doi:10.1111/ j.1365-3016.2012.01298.x

15 Hoffman DJ, Sawaya AL, Verreschi I, Tucker KL, Roberts SB. Why are nutritionally stunted children at increased risk of obesity? Studies of metabolic rate and fat oxidation in shantytown children from São Paulo, Brazil. Am J Clin Nutr 2000;72:702-7. doi:10.1093/ajcn/72.3.702

16 Hoffman DJ, Roberts SB, Verreschi I, et al. Regulation of energy intake may be impaired in nutritionally stunted children from the shantytowns of São Paulo, Brazil. J Nutr 2000;130:2265-70. doi:10.1093/ jn/130.9.2265

17 World Health Organization (WHO). Obesity and Inequities in Europe. Guidance for addressing inequities in overweight and obesity, 2014.

18 Hanson M, Barker M, Dodd JM, et al. Interventions to prevent maternal obesity before conception, during pregnancy, and post partum. Lancet Diabetes Endocrinol 2017;5:65-76. doi:10.1016/S2213 8587(16)30108-5

19 Administrative Committee on Coordination/ Sub-Committee on Nutrition. 4th report: the world nutrition situation: nutrition throughout the life cycle. In: The UN system's forum for nutrition. United Nations, 2000. 
20 Stephenson J, Heslehurst N, Hall J, et al. Before the beginning: nutrition and lifestyle in the preconception period and its importance for future health. Lancet 2018;391:1830-41. doi:10.1016/ S0140-6736(18)30311-8.

21 Camaschella C. Iron-deficiency anemia. N Engl J Med 2015;372:1832-43. doi:10.1056/ NEJMra1401038

22 Schümann K, Solomons NW. Perspective: what makes it so difficult to mitigate worldwide anemia prevalence? Adv Nutr 2017;8:401-8. doi:10.3945/ an.116.013847

23 World Health Organization. The global prevalence of anaemia in 2011. World Health Organization, 2011.

24 Corvalán C, Garmendia ML, Jones-Smith J, et al. Nutrition status of children in Latin America. Obes Rev 2017;18(Suppl 2):7-18. doi:10.1111/ obr.12571

25 Rivera J, Gonzalez de Cossio T. Pobreza, nutrición y salud. En: Los determinantes sociales de la salud en México, 2012

26 World Bank. New country classifications by income level: 2017-2018. https://blogs.worldbank.org/ opendata/new-country-classifications-incomelevel-2017-2018

27 Demographic and Health Survey). Wealth index construction. www.dhsprogram.com/topics/wealthindex/Wealth-Index-Construction.cfm.

28 Organisation for Economic Co-operation and Development. Obesity update 2017. www.oecd.org/ els/health-systems/Obesity-Update-2017.pdf.

29 Inchley J, Currie D, Young T, et al. Growing up unequal: gender and socioeconomic differences in young people's health and wellbeing, Health Behaviour in School aged Children (HBSC) Study, international report from the 2013/2014 survey. WHO Regional Office for Europe, 2016.

30 Popkin BM, Adair LS, Ng SW. Global nutrition transition and the pandemic of obesity in developing countries. Nutr Rev 2012;70:3-21. doi:10.1111/ j.1753-4887.2011.00456.x

31 Rivera JA, Pedraza LS, Martorell R, Gil A. Introduction to the double burden of undernutrition and excess weight in Latin America. Am J Clin Nutr 2014;100:1613S-6S. doi:10.3945/ ajcn.114.084806

32 Public Health England. Patterns and trends in child obesity: slide presentation. 2017. www.slideshare. net/PublicHealthEngland/patterns-and-trendsinchild-obesity-june-2017.

33 Ogden CL, Carroll MD, Lawman HG, et al. Trends in obesity prevalence among children and adolescents in the United States, 1988-1994 Through 20132014. JAMA 2016;315:2292-9. doi:10.1001/ jama.2016.6361

34 Bogard K, Murry VM, Alexander C. Perspectives on health equity and social determinants of health. In: Bogard K, Murry VM, Alexander C, eds. National Academy of Medicine. 2017.

35 World Health Organization). Double-duty actions for nutrition. Policy brief: World Health Organization, 2017

36 Pingali PL. Green revolution: impacts, limits, and the path ahead. Proc Natl Acad Sci U S A 2012;109:12302-8. doi:10.1073/ pnas.0912953109

37 Pingali P. Agricultural policy and nutrition outcomes: getting beyond the preoccupation with staple grains. Food Secur 2015;7:583-91. doi:10.1007/s12571 015-0461-x.

38 Dietz WH. Double-duty solutions for the double burden of malnutrition. Lancet 2017;390:2607-8. doi:10.1016/S0140-6736(17)32479-0

39 Matsungo TM, Kruger HS, Smuts CM, Faber M. Lipid-based nutrient supplements and linear growth in children under 2 years: a review. Proc Nutr Soc 2017:76:580-8. doi:10.1017/ S0029665117000283

40 Hess SY, Abbeddou S, Jimenez EY, et al. Smallquantity lipid-based nutrient supplements, regardless of their zinc content, increase growth and reduce the prevalence of stunting and wasting in young burkinabe children: a cluster-randomized trial. PLoS One 2015;10:e0122242. doi:10.1371/ journal.pone.0122242
41 USAID/Food and Nutrition Technical Assistance. Meeting report: evidence and programmatic considerations for the use of small quantity lipid based nutrient supplements for the prevention of malnutrition. 2016

42 Ohri-Vachaspati P, DeLia D, DeWeese RS, Crespo NC, Todd M, Yedidia MJ. The relative contribution of layers of the Social Ecological Model to childhood obesity. Public Health Nutr 2015;18:2055-66. doi:10.1017/S1368980014002365

43 Ruel MT, Alderman H, Maternal and Child Nutrition Study Group. Nutrition-sensitive interventions and programmes: how can they help to accelerate progress in improving maternal and child nutrition? Lancet 2013;382:536-51. doi:10.1016/S01406736(13)60843-0

44 Weisstaub G, Aguilar AM, Uauy R. Treatment and prevention of malnutrition in Latin America: focus on Chile and Bolivia. Food Nutr Bull 2014;35(Suppl):S39-46. doi:10.1177/15648265140352S106

45 Huicho L, Segura ER, Huayanay-Espinoza CA, et al, Peru Countdown Country Case Study Workin Group. Child health and nutrition in Peru within an antipoverty political agenda: a Countdown to 2015 country case study. Lancet Glob Health 2016;4:e414-26. doi:10.1016/S2214109X(16)00085-1

46 Victora CG, Aquino EM, do Carmo Leal M, Monteiro CA, Barros FC, Szwarcwald CL. Maternal and child health in Brazil: progress and challenges. Lancet 2011;377:1863-76. doi:10.1016/S01406736(11)60138-4

47 Pérez-Escamilla R. Food security and the 201530 Sustainable Development Goals: from human to planetary health. Current Developments in Nutrition 2017

48 Huda TM, Hayes A, El Arifeen S, et al. Social determinants of inequalities in child undernutrition in Bangladesh: aA decomposition analysis. Maternal \& Child Nutrition 2018;14(1):e12440-n/a.

49 Salam RA, MacPhail C, Das JK, Bhutta ZA. Effectiveness of Micronutrient Powders (MNP) in women and children. BMC Public Health 2013;13(Suppl 3):S22.

50 De-Regil LM, Suchdev PS, Vist GE, Walleser S, PeñaRosas JP. Home fortification of foods with multiple micronutrient powders for health and nutrition in children under two years of age. Cochrane Database Syst Rev 2011:(9):CD008959.

51 De-Regil LM, Jefferds MED, Peña-Rosas JP. Pointof-use fortification of foods with micronutrient powders containing iron in children of preschool and school-age. Cochrane Database Syst Rev 2017;11:CD009666.

52 World Health Organization. Strategies to prevent anaemia: recommendations from an expert group consultation. New Delhi, India, 5-6 December 2016.

53 McPherson K, Marsh K, Brown MT. Tackling obesities: future choices: modelling future trends in obesity and the impact on health. 2007. www.bis.gov.uk/assets/ foresight/docs/obesity/14.pdf.

54 Kumanyika SK, Obarzanek E, Stettler N, et al, American Heart Association Council on Epidemiology and Prevention, Interdisciplinary Committee for Prevention. Population-based prevention of obesity: the need for comprehensive promotion of healthful eating, physical activity, and energy balance: a scientific statement from American Heart Association Council on Epidemiology and Prevention, Interdisciplinary Committee for Prevention (formerly the expert panel on population and prevention science). Circulation 2008;118:428-64. doi:10.1161/ CIRCULATIONAHA.108.189702

55 Roberto CA, Swinburn B, Hawkes C, et al. Patchy progress on obesity prevention: emerging examples, entrenched barriers, and new thinking. Lancet 2015;385:2400-9. doi:10.1016/S01406736(14)61744-X

56 Scarborough P, Nnoaham KE, Clarke D, Capewell S, Rayner M. Modelling the impact of a healthy diet on cardiovascular disease and cancer mortality. I Epidemiol Community Health 2012;66:420-6. doi:10.1136/jech.2010.114520
57 Pearson-Stuttard J, Bandosz P, Rehm CD, et al. Reducing US cardiovascular disease burden and disparities through national and targeted dietary policies: A modelling study. PLOS Med 2017;14:e1002311. doi:10.1371/journal. pmed.1002311

58 Bleich SN, Economos CD, Spiker ML, et al. A systematic review of calorie labeling and modified calorie labeling interventions: impact on consumer and restaurant behavior. Obesity (Silver Spring) 2017;25:2018-44. doi:10.1002/oby.21940

59 National Academies of Sciences, Engineering, and Medicine. Front-of-package nutrition rating systems and symbols: promoting healthier choices. 2011. http://nationalacademies.org/HMD/Reports/2011/ Front-of-Package-Nutrition-Rating-Systems-andSymbols-Promoting-Healthier-Choices.aspx

60 Hersey JC, Wohlgenant KC, Arsenault JE, Kosa KM, Muth MK. Effects of front-of-package and shelf nutrition labeling systems on consumers. Nutr Rev 2013;71:1-14. doi:10.1111/nure.12000

61 Marteau TM, Hollands G), Kelly MP. Changing population behavior and reducing health disparities: exploring the potential of "choice architecture" interventions. In: Kaplan R, Spittel M, David D, eds. Population Health: Behavioral and Social Science Insights. Agency for Healthcare Research and Quality and Office of Behavioral and Social Sciences Research. National Institutes of Health, 2015: 105-26.

62 Adams J, Mytton O, White M, Monsivais P. Why are some population interventions for diet and obesity more equitable and effective than others? the role of individual agency. PLoS Med 2016;13:e1001990. doi:10.1371/journal.pmed.1001990

63 Pérez-Escamilla R, Sellen D. Equity in breastfeeding where do we go from here? J Hum Lact 2015;31:124. doi:10.1177/0890334414561062

64 Victora CG, Bahl R, Barros Al, et al, Lancet Breastfeeding Series Group. Breastfeeding in the 21st century: epidemiology, mechanisms, and lifelong effect. Lancet 2016;387:475-90. doi:10.1016/S0140-6736(15)01024-7

65 Pérez-Escamilla R. Is breastfeeding protective against childhood obesity? 2016. https://nam.edu/canbreastfeeding-protect-against-childhood-obesity.

66 Pérez-Escamilla R, Lutter CK, Rabadan-Diehl C, et al. Prevention of childhood obesity and food policies in Latin America: from research to practice. Obes Rev 2017;18(Suppl 2):28-38. doi:10.1111/ obr.12574

67 Oken E, Fields DA, Lovelady CA, Redman LM. TOS scientific position statement: breastfeeding and obesity. Obesity (Silver Spring) 2017;25:1864-6. doi:10.1002/oby. 22024

68 Neville CE, McKinley MC, Holmes VA, Spence D, Woodside JV. The relationship between breastfeeding and postpartum weight change--a systematic review and critical evaluation. Int J Obes (Lond) 2014:38:577-90. doi:10.1038/ijo.2013.132

69 López-Olmedo N, Hernández-Cordero S, Neufeld LM, García-Guerra A, Mejía-Rodríguez F, Méndez GómezHumarán I. The associations of maternal weight change with breastfeeding, diet and physical activity during the postpartum period. Matern Child Health / 2016;20:270-80. doi:10.1007/s10995-0151826-7

70 Horta BL, Loret de Mola C, Victora CG. Long-term consequences of breastfeeding on cholesterol, obesity, systolic blood pressure and type 2 diabetes: a systematic review and meta-analysis. Acta Paediatr 2015;104:30-7. doi:10.1111/apa.13133

71 NCD Risk Factor Collaboration (NCD-RisC). Worldwide trends in body-mass index, underweight, overweight, and obesity from 1975 to 2016: a pooled analysis of 2416 population-based measurement studies in 128.9 million children, adolescents, and adults. Lancet 2017;390:2627-42. doi:10.1016/S01406736(17)32129-3

72 NCD Risk Factor Collaboration (NCD-RisC). Trends in adult body-mass index in 200 countries from 1975 to 2014: a pooled analysis of 1698 population-based measurement studies with 19.2 million participants. Lancet 2016;387:1377-96 doi:10.1016/S0140-6736(16)30054-X 
73 Flegal KM, Kruszon-Moran D, Carroll MD, Fryar CD Ogden CL. Trends in obesity among adults in the United States, 2005 to 2014. JAMA 2016;315: 2284-91. doi:10.1001/jama.2016.6458

74 Breastfeeding: achieving the new normal. Lancet 2016;387:404. doi:10.1016/S01406736(16)00210-5

75 Rasmussen KM, Whaley SE, Perez-Escamilla R, et al. New opportunities for breastfeeding promotion and support in WIC: review of WIC food packages, improving balance and choice. J Nutr Educ Behav 2017;49(7S2):S197-S201 e1.

76 Chapman DJ, Morel K, Anderson AK, Damio G, PérezEscamilla R. Breastfeeding peer counseling: from efficacy through scale-up. J Hum Lact 2010;26: 314-26. doi:10.1177/0890334410369481

77 Pérez-Escamilla R, Martinez JL, Segura-Pérez S. Impact of the Baby-friendly Hospital Initiative on breastfeeding and child health outcomes: a systematic review. Matern Child Nutr 2016;12: 402-17. doi:10.1111/mcn.12294

78 Lutter CK, Chaparro CM, Grummer-Strawn LM. Increases in breastfeeding in Latin America and the Caribbean: an analysis of equity. Health Policy Plan 2011;26:257-65. doi:10.1093/heapol/czq046

79 Pérez-Escamilla R, Curry L, Minhas D, et al. Scaling up of breastfeeding promotion programs in lowand middle-income countries: the "breastfeeding gear" model. Advances in nutrition (Bethesda, Md) 2012;3(6):790-800

80 World Health Organization. The International Code of Marketing of Breast-milk Substitutes: Frequently Asked Questions (2017 Update). World Health Organization, 2017.

81 Rollins NC, Bhandari N, Hajeebhoy N, et al, Lancet Breastfeeding Series Group. Why invest, and what it will take to improve breastfeeding practices? Lancet 2016;387:491-504. doi:10.1016/S01406736(15)01044-2

82 Reifsnider E, Allan J, Percy M. Mothers' explanatory models of lack of child growth. Public Health Nurs 2000;17:434-42. doi:10.1046/j.15251446.2000.00434.x

83 Story M, Hannan PJ, Fulkerson JA, et al. Bright Start: Description and main outcomes from a group-randomized obesity prevention trial in American Indian children. Obesity (Silver Spring) 2012;20:2241-9. doi:10.1038/oby.2012.89

84 Crawford L, Howard J, Karmali R, et al. Childhood obesity and possible policy interventions. Georgia Institute of Technology, 2013.

85 Monteiro CA, Cannon G, Moubarac J-C, Levy RB, Louzada MLC, Jaime PC. The UN Decade of Nutrition, the NOVA food classification and the trouble with ultra-processing. Public Health Nutr 2017:21;1-13.

86 Monteiro CA, Moubarac JC, Cannon G, Ng SW, Popkin B. Ultra-processed products are becoming dominant in the global food system. Obes Rev 2013;14(Suppl 2):21-8. doi:10.1111/ obr.12107

87 Franck C, Grandi SM, Eisenberg MJ. Agricultural subsidies and the American obesity epidemic Am J Prev Med 2013;45:327-33. doi:10.1016/j. amepre.2013.04.010

88 Puska P. Successful prevention of non-communicable diseases: 25 year experiences with North Karelia Project in Finland. Public Health Medicine 2002;4:5-7.

89 Fernald LCH, Gertler PJ, Hou X. Cash component of conditional cash transfer program is associated with higher body mass index and blood pressure in adults. J Nutr 2008;138:2250-7. doi:10.3945/ jn.108.090506

90 Bassett L. Can conditional cash transfer programs play a greater role in reducing child undernutrition? In: World Bank, Discussion Paper, 2008.

91 Segura-Pérez S, Grajeda R, Pérez-Escamilla R. Conditional cash transfer programs and the health and nutrition of Latin American children. Rev Panam Salud Publica 2016;40:124-37.

92 Forde I, Chandola T, Garcia S, Marmot MG, Attanasio $\mathrm{O}$. The impact of cash transfers to poor women in Colombia on BMI and obesity: prospective cohort study. Int J Obes (Lond) 2012;36:1209-14. doi:10.1038/ijo.2011.234

93 de Bem Lignani J, Sichieri R, Burlandy L, SallesCosta R. Changes in food consumption among the Programa Bolsa Família participant families in Brazil. Public Health Nutr 2011;14:785-92. doi:10.1017/ S136898001000279X

94 Le HND, Gold L, Abbott G, et al. Economic evaluation of price discounts and skill-building strategies on purchase and consumption of healthy food and beverages: The SHELf randomized controlled trial. Soc Sci Med 2016;159(Supplement C):83-91. doi:10.1016/j.socscimed.2016.04.015

95 Ni Mhurchu C, Blakely T, Jiang Y, Eyles HC, Rodgers A Effects of price discounts and tailored nutrition education on supermarket purchases: a randomized controlled trial. Am J Clin Nutr 2010;91:736-47. doi:10.3945/ajen.2009.28742

96 Waterlander WE, de Boer MR, Schuit AJ, Seidell JC, Steenhuis IH. Price discounts significantly enhance fruit and vegetable purchases when combined with nutrition education: a randomized controlled supermarket trial. Am J Clin Nutr 2013;97:886-95 doi:10.3945/ajen.112.041632

97 Klerman JA, Bartlett S, Wilde P, Olsho L. The short-run impact of the healthy incentives pilot program on fruit and vegetable intake. Am J Agric Econ 2014;96:1372-82. doi:10.1093/ajae/aau023.

98 Colchero MA, Salgado JC, Unar-Munguía M, Molina M, $\mathrm{Ng}$ S, Rivera-Dommarco JA. Changes in prices after an excise tax to sweetened sugar beverages was implemented in Mexico: evidence from urban areas.
PLoS One 2015;10:e0144408. doi:10.1371/ journal.pone.0144408

99 World Health Organization. Using price policies to promote healthier diets. Regional Office for Europe. 2015.

100 Caro JC, Ng SW, Taillie LS, et al. Designing a tax to discourage unhealthy food and beverage purchases: the case of Chile. Food Policy 2017;71(Supplement C):86-100. doi:10.1016/i.foodpol.2017.08.001

101 Alvarado M, Kostova D, Suhrcke M, et al, Barbados SSB Tax Evaluation Group. Trends in beverage prices following the introduction of a tax on sugar-sweetened beverages in Barbados. Prev Med 2017;105S(Supplement):S23-5. doi:10.1016/j.ypmed.2017.07.013

102 Falbe J, Thompson HR, Becker CM, Rojas N, McCulloch CE, Madsen KA. Impact of the Berkeley excise tax on sugar-sweetened beverage consumption. Am J Public Health 2016;106 1865-71. doi:10.2105/AJPH.2016.303362

103 Ministry of Health of Brazil. Guia alimentar para a população brasileira/Dietary guidelines for the Brazilian population. Brasília: Ministério da Saúde, Secretaria de Atenção à Saúde, Departamento de Atenção Básica, 2014.

104 Millen BE, Abrams S, Adams-Campbell L, et al. The 2015 dietary guidelines advisory committee scientific report: development and major conclusions. Adv Nutr 2016;7:438-44. doi: 10.3945/an.116.012120

105 Pérez-Escamilla R. The Mexican dietary and physical activity guidelines: moving public nutrition forward in a globalized world. J Nutr 2016;146:1924S-7S. doi:10.3945/jn.115.218784

106 Food and Agriculture Organization of the United Nations. Food-based dietary guidelines. Secondary Food-based dietary guidelines 2017. www.fao. org/nutrition/education/food-dietary-guidelines/ background/en.

107 Pérez-Escamilla R, Segura-Pérez S, Lott M. Feeding guidelines for infants and young toddlers: a responsive parenting approach. 2017. http:// healthyeatingresearch.org/wp-content/ uploads/2017/02/her_feeding_guidelines report_021416-1.pdf

108 Hawkes C, Demaio AR, Branca F. Double-duty actions for ending malnutrition within a decade. Lancet Glob Health 2017;5:e745-6. doi:10.1016/S2214 109X(17)30204-8

109 Boccolini CS, Boccolini PMM, Monteiro FR, Venâncio SI, Giugliani ERJ. Breastfeeding indicators trends in Brazil for three decades. Rev Saude Publica 2017;51:108. doi:10.11606/S15188787.2017051000029

Cite this as: BMJ 2018;361:j2252

http://dx.doi.org/10.1136/bmj.j2252

This is an Open Access article distributed in accordance with the terms of the Creative Commons Attribution (CC BY 4.0) license, which permits others to distribute, remix, adapt and build upon this work, for commercial use, provided the original work is properly cited. See: http:// creativecommons.org/licenses/by/4.0/ 